\title{
Análisis del paisaje en el Parque Arqueológico "Las Piedras del Tunjo", mediante la caracterización vegetal arbórea
}

Landscape Analysis in the Archaeological Park "Las Piedras del Tunjo" through the Tree-like Plant Characterization

William Ricardo Diaz Santamaria a

Universidad Nacional Abierta y a Distancia, Colombia

william.diaz@unad.edu.co

ORCID: http://orcid.org/0000-0002-6973-3398
DOI: https://doi.org/10.11144/Javeriana.ayd22-42.appa Redalyc: http://www.redalyc.org/articulo.oa? $\mathrm{id}=151557418003$

Fecha de recepción: 25 Noviembre 2017 Fecha de publicación: 30 Junio 2018

\section{Resumen:}

El Parque Arqueológico "Las Piedras del Tunjo" es considerado como un área de gran relevancia ancestral para la región. Las manifestaciones rupestres le han dado la importancia patrimonial que lo hacen resaltar a nivel nacional. Sin embargo, su funcionalidad contempla otros aspectos, además del cultural. El hecho que sea considerado como parte de la Estructura Ecológica Principal para el municipio de Facatativá y para el departamento de Cundinamarca, así como un lugar de recreación para los habitantes de la región, le otorgan una relevancia mayor. El presente estudio analiza el paisaje del parque arqueológico, enfatizando en las especies vegetales arbóreas y su significancia frente a la multifuncionalidad del lugar. Se constituye de esta manera en una herramienta para la planificación y la configuración de espacios que posibiliten la articulación de los ámbitos cultural, recreativo y ecosistémico.

Palabras clave: paisaje, multifuncionalidad, territorio, oferta ambiental.

\section{Abstract:}

The archaeological park "Las Piedras del Tunjo" [Tunjo's Stones] is an area of great ancestral relevance in the region. The rock art expressions have conferred it a heritage significance that is recognized in the whole country. However, its functionality includes different aspects besides the cultural. The fact that it is deemed as a part of the Main Ecological Structure in both the town Facatativá and the Cundinamarca Province, as well as a recreation place for the local inhabitants, makes this park even more signi ficant. This study examines the landscape of the archaeological park, emphasizing the tree-like plant species and their significance regarding the park multi-functionality. This way, this work serves as a tool for planning and shaping spaces that would enable to articulate the cultural, recreational and ecosystemic spheres.

Keywords: landscape, multi-functionality, territory, environmental offer.

\section{Introducción}

El Parque Arqueológico "Piedras del Tunjo", ubicado en el municipio de Facatativá, se constituye en un área ecológica de especial relevancia para la academia, así como para la recreación pasiva; su eje articulador lo configuran sus relictos ancestrales que le otorgan un gran valor arqueológico para la Nación. Así mismo, representa un área de gran riqueza ecosistémica, con impactos significativos ocasionados por la intervención antrópica (Instituto Colombiano de Antropología e Historia [Icanh], 2005), donde confluyen especies características del bosque altoandino.

Pese a ello, la riqueza ambiental que posee y la contribución a la oferta turística no han sido suficientemente identificadas y valoradas. El desconocimiento de los beneficios sociales que aporta la biodiversidad es uno de los factores que determinan los rápidos procesos de transformación y deterioro de los paisajes naturales (Icanh, 2005). En tal sentido, el uso, conservación y manejo racional requieren un conocimiento previo del estado de las poblaciones y distribuciones ecosistémicas.

Es notable que el Parque Arqueológico "Piedras del Tunjo" se configure como un escenario de gran valor ancestral para el territorio colombiano, debido a las huellas históricas que reposan sobre sus rocas. Los pictogramas reflejan, en parte, las representaciones culturales de las comunidades indígenas que habitaron el 
lugar. Aunado a ello, el parque adquiere una relevancia mayor al encontrarse dentro de un contexto urbano cercano a la capital de la República. Esta condición repercute notablemente dado que el lugar adquiere una función social como reserva y sitio predilecto para la recreación.

De una parte, partiendo del principio que el eje central y articulador de cualquier uso en el área está considerado por su importancia patrimonial, y dada su multiplicidad funcional y la relevancia ecosistémica y recreativa, surge la necesidad de estudiar la configuración del paisaje para evaluar el grado de integración de los usos mencionados. Hasta el momento, no se cuenta con investigaciones que aborden a profundidad la composición florística presente en el área de influencia directa del Parque Arqueológico "Las Piedras del Tunjo"; aunque sí se tiene información preliminar de las especies que caracterizan el área por estudios generales realizados por la Corporación Autónoma Regional de Cundinamarca - CAR y el Icanh (Icanh, 2005).

De otra, el Parque Arqueológico es utilizado bajo ámbitos culturales, lúdicos y recreativos, pero ¿̇cómo está configurado paisajísticamente para que estos diferentes usos se puedan albergar sin olvidar el sentido ancestral de su constitución? La administración del municipio de Facatativá y el Icanh han efectuado acciones encaminadas a la conservación de los pictogramas, la restricción de usos en áreas estratégicas y la puesta en marcha de mecanismos que busquen el uso adecuado por parte de los visitantes del lugar. No obstante, la conformación de este escenario trasciende las connotaciones ancestrales que permitieron su promulgación como área patrimonial, debido a que es evidente su utilización como espacio de recreación pasiva y de importancia ecosistémica para la región.

Esta perspectiva de análisis se fundamenta en la base del presente estudio, en el cual se evalúa paisajísticamente el Parque Arqueológico "Las Piedras del Tunjo", empleando para ello, los individuos y especies vegetales de carácter arbóreo y arbustivo.

\section{Configuración e importancia del paisaje en parques arqueológicos}

La base para la declaración del área como parque arqueológico se fundamenta en los relictos ancestrales (pictogramas) que reposan sobre el complejo rocoso. Sin embargo, el parque está compuesto por más elementos paisajísticos (vegetación, senderos, zonas duras) de los cuales se desprenden los diferentes usos del lugar.

El estudio del paisaje del Parque Arqueológico constituye un instrumento y una herramienta útil para orientar su funcionamiento hacia un futuro, lo que preserva su identidad patrimonial y su funcionalidad ecológica y de escenario recreativo.

La Real Academia de la Lengua Española, define "paisaje" como aquella parte de un territorio que puede ser observada desde un determinado lugar; como un espacio natural admirable por su aspecto artístico. Complementa la definición indicando que un "paisaje protegido" es aquel espacio natural que, por sus valores estéticos y culturales, es objeto de protección legal para garantizar su conservación. La percepción del territorio por parte de la población define el paisaje cuando en él se denotan los resultados de la acción y la interacción de factores naturales y/o humanos (Consejo de Europa, 2000). La disposición de objetos visibles percibidos por los sujetos parte de los filtros, la sensibilidad y las finalidades propias, por ende, el paisaje varía de acuerdo a las sociedades, personas, culturas y modos de vida (Organización de las Naciones Unidas para la Agricultura y la Alimentación [FAO], 2003) Al respecto, Gómez-Alzate (2012) determina que

El paisaje juega un papel esencial en la configuración de toda ciudad contemporánea, y es parte sustancial de la calidad de vida urbana, que a partir del paradigma de la sostenibilidad y de la ecología, se integra con mucha fuerza en la planificación de las ciudades de diversa magnitud en distintas escalas. (p.1)

El paisaje requiere, por lo tanto, de una mirada interdisciplinar. Montoya-Ayala, Padilla- Ramírez y Stanford-Camargo (2003) mencionan que 
el objetivo no es dictar normas de estudio, sino explorar posibilidades y obtener un valor del paisaje en función de su atractivo o por la evaluación de su menor o mayor susceptibilidad al cambio cuando se desarrolla un uso sobre él. (p.1)

El paisaje, considerado como recurso ambiental, territorial, cultural y económico, forma parte integral de la ordenación del territorio y la planificación urbanística; es un instrumento clave para establecer los objetivos, principios, estrategias y directrices que permitirán identificar y diseñar las actuaciones y puesta en valor del paisaje en cualquier escala del territorio (Muñoz-Criado, 2012).

De esta manera, el estudio del paisaje es analizado desde sus diferentes componentes físicos, bióticos y de actuaciones humanas, y permite acercarse al entendimiento del lugar al comprender su vínculo social, la aproximación al reflejo de la realidad y su evolución a lo largo del tiempo (Másmela-Díaz, 2010).

Es importante resaltar que el paisaje va mucho más allá de la percepción visual de la realidad sensible; la cultura está inmersa en su entorno y, por ello, las comunidades se reconocen en él (Arias citado por MuñozCamacho, 2015). Aponte-García (2003) determina que el paisaje forma nuestro carácter, alimenta el espíritu y estimula la creatividad.

Para abordar el paisaje, o al menos acercase a su conocimiento, se requiere de la comprensión de los sistemas natural y cultural, en razón a que en un mismo espacio confluyen e integran organismos, objetos, lugares y acciones (Gómez-Alzate, 2012).

Las acciones antrópicas juegan un papel preponderante en el paisaje al intervenir directamente en el entorno mediante la implementación de actividades agrícolas, pecuarias, de infraestructura vial, urbanización y acciones turísticas y deportivas (Másmela-Díaz, 2010).

Los parques arqueológicos se fundamentan en el reconocimiento y protección del patrimonio, y se convierten en escenarios propicios para la conservación, investigación, educación y divulgación de los bienes culturales de la Nación (Icanh, 2005). De igual manera, se han constituido como instrumentos para la protección y gestión del patrimonio arqueológico, pero también como un marco para enfocar la investigación sobre el paisaje, en el cual confluyen las interrelaciones entre hombre y el medio, y están inmersas las huellas de las actividades antiguas (Orejas-Saco-del-Valle, 2001). Caballero-Calderón (citado por Cobo-Borda, 2010) resalta al respecto, "El paisaje: un escenario apenas para que sombras y aparecidos se deslizaran como rencores vivos".

Para la Unesco (citado por Pérez-Bustamante \& Parra-Ponce, 2004), los paisajes representan

los trabajos combinados de la naturaleza y el hombre. Ellos son ilustrativos de la evolución de la sociedad humana en el tiempo, bajo la influencia de las limitaciones y/o oportunidades físicas presentadas por su ambiente natural y de sucesivas fuerzas sociales, económicas y culturales, tanto externas como internas. (p.12)

Cuando se lleva a cabo el análisis del paisaje, se accede a las formas de intervención que tuvieron lugar en él, se lograrán llevar a cabo acercamientos sobre la estructura y la evolución de las sociedades y las formas de poder (Sánchez-Palencia et al., 1996).

La Unesco señala que los paisajes revelan la diversidad de interacciones entre las comunidades y su entorno, al tiempo que protegen las culturas tradicionales de vida y preservan los restos de aquellas que han desaparecido. Existe, por lo tanto, una conexión entre el patrimonio arqueológico y el paisaje, que conlleva a nuevas herramientas, procedimientos y criterios para la comprensión del paisaje (Gómez-Zotano \& RiescoChueca, 2010). En este sentido, el parque arqueológico es el escenario propicio, y da excelentes perspectivas para la protección e investigación de paisajes antiguos (Orejas-Saco-del-Valle, 2001), o, como lo mencionan Ayuso-Álvarez et al. (2013)

Todo paisaje refleja la cultura territorial de la sociedad que a lo largo de los siglos lo ha elaborado. Por esta misma razón, el paisaje se convierte en factor de identidad, recurso patrimonial y elemento singular de cada ámbito geográfico. (p.58) 


\section{El Parque Arqueológico "Las Piedras del Tunjo” y sus múltiples connotaciones funcionales}

El Parque Arqueológico Nacional de Facatativá, conocido, también, como "Piedras del Tunjo", "Piedras de Tunja”, "Cercado del Zipa” (ICANH, 2005), "Cercado de Tisquesusa” (Ramírez citado por Martínez, 2011), y bajo la tradición popular como "Piedras del Diablo" (Botiva-Contreras, 2011), se encuentra localizado en el municipio de Facatativá (Cundinamarca), en el extremo noroccidental de la Sabana de Bogotá, y alberga en sus cerca de 27 hectáreas, un enorme patrimonio cultural y ecosistémico representado, entre otros, por sus abrigos rocosos, sus pinturas rupestres y su paisaje de gran riqueza visual y medio ambiental (Martínez, 2011).

Las referencias científicas e investigativas se han efectuado desde hace décadas. Tan solo en el año 1912, José Miguel Rosales hacía referencia al paisaje prístino del parque: "Imagínese lo que sería este recinto rodeado de árboles y protegido por una estacada estilo chibcha, con su prado natural esmaltado de flores y sombreado por bosquecillos de gaques, salvios y arrayanes" (p.6).

Si bien fue declarado como Parque Arqueológico Nacional mediante el Decreto 684 de 1946, el reconocimiento de su importancia ecosistémica, cultural y arqueológica datan del siglo XIX, cuando, en ese entonces, el Presidente de la República, Carlos Holguín, promulga mediante el Decreto 560 de 1889 que en el área se debe levantar un monumento, teniendo en cuenta la "belleza natural y artística" (Olivos-Lombana, 2011).

El hecho que el parque limite con el casco urbano del municipio de Facatativá, y esté a tan solo $40 \mathrm{~km}$ de la ciudad de Bogotá D.C., lo convierte en un escenario donde convergen su funcionalidad como patrimonio cultural, zona de reserva de interés especial dentro de la estructura ecológica principal del municipio y del departamento de Cundinamarca, y como un espacio para la recreación, el descanso, las ofertas culturales y el turismo (Icanh, 2005).

Ahora bien, esta multiplicidad de funciones (que para el presente estudio se categorizarán en cultura, recreación y servicios ecosistémicos), bajo una concepción no integradora, ha ocasionado que durante años se haya deteriorado el patrimonio arqueológico a raíz de la implementación de prácticas de recreación activa: el tradicional "paseo de olla", los eventos públicos masivos, la falta de una delimitación adecuada de los sitios rupestres, actos de vandalismo, alteraciones en el arte rupestre a raíz de grafitis, el rayado de la roca con materiales como carbón y los vinilos, el hollín producto de las fogatas llevadas a cabo durante muchos años del siglo XX y el dinamitado, aunado a las alteraciones de origen natural (agrietamiento) provocado por las raíces de los árboles que crecen sobre la roca sin que se den las medidas silviculturales propias para el mantenimiento adecuado de la vegetación en una zona de reserva (pero también de sano esparcimiento), evidencian la desarticulación en su concepción holística en el área protegida.

El Plan de Manejo establecido por el Icanh en el 2005 estableció una propuesta de zonificación de áreas dentro del Parque, en la cual se reconoce sus funciones diversas y se establecen áreas para la reserva natural, áreas arqueológicas y la recreación pasiva, áreas de recreación activa y áreas administrativas y de servicios.

Cada una de estas presenta unas connotaciones básicas que deben regular su uso.

- El área de reserva natural se presenta como aquella zona con preponderancia de árboles y arbustos, empleada para la delimitación del parque y como amortiguación con el entorno. Allí se prohíben las actividades de recreación activa.

- El área arqueológica y de recreación pasiva, constituida por los abrigos rocosos que poseen las manifestaciones rupestres, los senderos interpretativos, vallas y paneles informativos, y estaciones y puntos de información.

- El área de recreación activa está conformada por los sectores donde existe infraestructura física que permite la realización de actividades como navegación, deportes y caminatas. 
- Por último, se encuentran las edificaciones para la realización de las funciones administrativas y de prestación de servicios.

En el presente estudio, dicha multiplicidad de funciones y particularidades del parque es analizada desde el componente vegetal, elemento constitutivo del paisaje que vislumbra la historia y la representatividad cultural y ecosistémica del área.

\section{Caracterización vegetal - Metodología}

La vegetación presente en un lugar determinado puede ser considerada como un indicador de los procesos naturales y acciones antrópicas que han acontecido a lo largo del tiempo. En este sentido, el Parque Arqueológico "Las Piedras del Tunjo" ha sufrido cambios rotundos dada la introducción de especies exóticas y al escaso manejo silvícola debido a los individuos arbóreos.

Muñoz-Criado (2012) menciona que los sistemas de vegetación:

son uno de los elementos clave para analizar un paisaje. Su distribución en el territorio responde a fenómenos naturales o derivados de la gestión antrópica del territorio. El modo en el que se organiza la cubierta vegetal de un lugar determina de una manera muy marcada el carácter del paisaje. (p.64)

El plan de manejo del parque, elaborado por el Icanh en el 2005, menciona que en la zona hacen fuerte presencia las especies de acacia, pino y ciprés, así como de pasto kikuyo, lo que desplaza las especies vegetales nativas. No obstante, no hace alusión a algún inventario forestal que permita obtener con certeza indicadores sobre la representatividad de cada una de las especies arbóreas existentes en la zona.

La deficiencia en la información sobre el análisis del paisaje del Parque Arqueológico, que integre los valores culturales, recreativos y ecosistémicos, se convierte en la oportunidad de investigación y en la base del presente estudio. Es así como por medio de la caracterización de la vegetación se logra realizar un acercamiento a la complejidad del paisaje y su articulación con la multifuncionalidad del parque. Lejos de pretender realizar un proyecto complejo de caracterización florística, llevó a cabo un inventario (conteo) de las especies arbóreas y arbustivas, su correspondiente georreferenciación y la toma de datos básicos, como el diámetro de la copa, que posibilitan la obtención de indicadores de diversidad.

El inventario forestal se efectuó durante el primer semestre del 2016, en la totalidad del área del Parque, e incluyó el 100\% de los individuos arbóreos y arbustivos presentes en la zona que tuviesen, como mínimo, 10 centímetros de diámetro a la altura del pecho (ítem empleado comúnmente en los inventarios forestales).

Se registró información relacionada con las especies, el porte y el diámetro de la copa, así como la correspondiente georreferenciación, empleando para ello un GPS marca Garmin, referencia eTrex - 10. La información levantada en campo fue digitalizada en una hoja de cálculo e importada al software libre QGIS (versión 2.14), con el propósito de obtener mapas temáticos que coadyuven a la comprensión de la distribución y cobertura de la vegetación en el lugar.

Como parte de las acciones llevadas a cabo en el ejercicio de caracterización vegetal, se procedió a digitalizar la imagen satelital procedente de Google Earth en el software libre QGIS (versión 2.14), con el objeto de delimitar la zona de estudio (área del parque) y establecer las coberturas vegetales presentes en el lugar, lo que facilita la posterior inclusión de cada uno de los puntos correspondientes a los individuos arbóreos.

Partiendo de los métodos para el análisis de biodiversidad del Instituto Alexander von Humboldt, se calcula la abundancia relativa y dominancia relativa de las especies vegetales, en cada una de las zonas previstas en el plan de manejo.

Así mismo, basados en los datos de georreferenciación de las especies vegetales, se procedió a efectuar el análisis de distribución espacial y a determinar el comportamiento de la cobertura vegetal en el área. Ahora bien, para complementar la observación de este último ítem, y tomando como base las imágenes satelitales 
disponibles en la aplicación Google Earth, se llevó a cabo la comparación espacial de vegetación para los años 2004 y 2015.

\section{Resultados - Análisis estructural}

Mediante la realización del inventario forestal se encontró que en el Parque Arqueológico se encuentran 2592 individuos vegetales, 1368 individuos de porte arbóreo y 1206 de porte arbustivo, pertenecientes a 34 familias botánicas y 53 especies, tal como se describe en la tabla 1.

TABLA 1 .

Individuos vegetales por familia botánica

\begin{tabular}{cccc}
\hline Familia botánica & $\begin{array}{c}\text { Número de } \\
\text { individuos } \\
\text { vegetales }\end{array}$ & Familia botánica & $\begin{array}{c}\text { Número de } \\
\text { individuos } \\
\text { vegetales }\end{array}$ \\
\hline Adoxaceae & 78 & Meliaceae & 17 \\
\hline Araucariaceae & 4 & Moraceae & 25 \\
\hline Arecaceae & 5 & Musaceae & 1 \\
\hline Asparagaceae & 10 & Myrsinaceae & 11 \\
\hline Asteraceae & 30 & Myrtaceae & 379 \\
\hline Betulaceae & 39 & Nyctaginaceae & 1 \\
\hline Bignoniaceae & 138 & Oleaceae & 98 \\
\hline Cupressaceae & 71 & Onagraceae & 2 \\
\hline Elaeocarpaceae & 6 & Papaveraceae & 4 \\
\hline Escalloniaceae & 37 & Pinaceae & 56 \\
\hline Euphorbiaceae & 53 & Piperaceae & 23 \\
\hline Fagaceae & 33 & Pittosporaceae & 273 \\
\hline Lauraceae & 3 & Podocarpaceae & 4 \\
\hline Leguminosae & 900 & Rosaceae & 74 \\
\hline Lythraceae & 13 & Salicaceae & 149 \\
\hline Magnoliaceae & 1 & Solanaceae & 1 \\
\hline Melastomataceae & 22 & Verbenaceae & 31 \\
\hline
\end{tabular}

Fuente: elaboración propia

El 59,88\% de los individuos vegetales (1552 individuos) está representado por tres familias botánicas: Leguminosae, Myrtaceae y Pittosporaceae, las cuales incluyen especies vegetales exóticas o introducidas como acacia (Acacia sp), eucalipto (Eucalyptus globulus) y jazmín (Pittosporum undulatum). 
TABLA 2 .

Principales especies presentes en el parque arqueológico

\begin{tabular}{lccc}
\hline \multicolumn{1}{c}{ Nombre científico } & \multicolumn{2}{c}{ Procedencia } & $\begin{array}{c}\text { Número de } \\
\text { individuos } \\
\text { vegetales }\end{array}$ \\
\cline { 2 - 3 } & Introducida & Nativa & 438 \\
\hline Acacia melanoxylon R.Br. & $\mathrm{X}$ & 397 \\
\hline Acacia decurrens Willd & $\mathrm{X}$ & 356 \\
\hline Eucalyptus globulus Labill & $\mathrm{X}$ & 273 \\
\hline Pittosporum undulatum Vent & $\mathrm{X}$ & & 98 \\
\hline Fraxinus chinensis Roxb. & $\mathrm{X}$ & & 138 \\
\hline Tecoma stans (L) Juss. Ex Kunth & & $\mathrm{X}$ & 111 \\
\hline $\begin{array}{l}\text { Xylosma spiculifera } \text { (Tul.) Triana y } \\
\text { Planch }\end{array}$ & & $\mathrm{X}$ & 78 \\
\hline Sambucus peruviana Kunth & & $\mathrm{X}$ & 62 \\
\hline $\begin{array}{l}\text { Senna viarum } \text { (Little) HSIrwin y } \\
\text { Barneby }\end{array}$ & $\mathrm{X}$ & \\
\hline Croton sp & & $\mathrm{X}$ & 53 \\
\hline
\end{tabular}

Fuente: elaboración propia

De una parte, con base en la información de la tabla 2, se obtiene información clave para acercarnos al entendimiento del paisaje presente en el parque arqueológico. En la figura 1 se evidencia la localización de las especies vegetales introducidas y las nativas. El 69,25\% del total de los individuos vegetales presentes en el área son exóticos o introducidos, de los cuales el 46,47\% corresponden al género Acacia (especies Acacia decurrens y A. melanoxylon); el 19,81\%, a la especie eucalipto (Eucalyptus globulus); y el 15,19\%, a la especie Jazmín (Pittosporum undulatum). Los individuos vegetales comúnmente reconocidos como coníferas, correspondientes a las especies ciprés (Cupressus lusitanica), pino (Pinus radiata y P. patula) y araucaria (Araucaria sp) representan el 7,29\% del total de los individuos vegetales exóticos o introducidos.
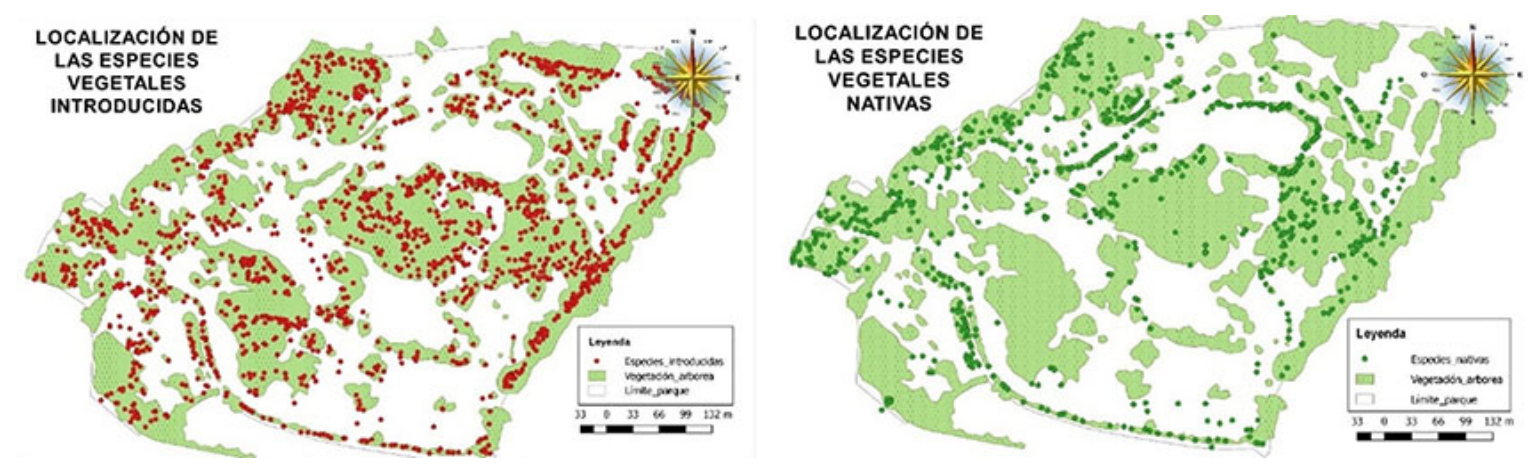

FIGURA 1.

Ubicación especies vegetales en el Parque Arqueológico.

Fuente: elaboración propia - empleando el Software QGis versión 2.14 
De otra, las principales especies nativas que se encuentran en el parque corresponden a Chicalá (Tecoma stans) con una representatividad del 17,36\%; Corono (Xylosma spiculifera), con un 13,97\%; Sauco (Sambucus peruviana), con el 9,81\%; Alcaparro (Senna viarum), con un 7,78\%; y Drago (Croton sp), con el 6,67\%.

Ahora bien, el hecho que haya un mayor número de individuos vegetales por determinada especie, no necesariamente indica que ella tenga una mayor cobertura. Por lo tanto, empleando la proyección de la copa sobre el suelo, se procedió a calcular el indicador de cobertura para cada una de las especies vegetales, y se encontró que las especies exóticas o introducidas poseen una cobertura del 83,09\% de la zona de estudio, siendo la especie Eucalipto (Eucalyptus globulus) la de mayor cobertura vegetal entre las especies introducidas, con un 27,85\%. Le siguen las especies conocidas como Acacias (Acacia decurrens y A. melanoxylon), con un 26,69\%; y, por último, la especie Jazmín (Pittosporum undulatum), con un 6,53\%.

Con relación a las especies nativas, estas presentan una cobertura del 16,91\%, siendo la de mayor representatividad la especie Chicalá (Tecoma stans), con un 17,03\%; seguida de la especie Alcaparro (Senna viarum), con el 5,59\%; y, en tercer lugar, el Sauce (Salix bumboldtiana), con un 5,43\%.

\section{Distribución de especies y uso de suelo}

El plan de manejo del parque arqueológico elaborado en el 2005 por el Icanh, señala tres categorías de uso para el lugar, y las especifica mediante la propuesta de zonificación. Es así como se determina el área de reserva natural, el área arqueológica (recreación pasiva) y el área de recreación activa.

La caracterización vegetal para cada una de estas áreas otorga una visión de paisaje con una mayor especificidad, y otorga herramientas para abordar la multifuncionalidad del parque arqueológico, así como el establecimiento de limitantes y potencialidades que permitan fijar las acciones tendientes a la gestión integral en el lugar. Es notorio que las especies exóticas predominan en el parque y, en cada una de las tres categorías de uso establecidas (tabla 3), la incorporación de especies como acacias, eucaliptos, pinos y jazmines solo ejemplifican y denotan la inclusión de dichas especies en proyectos de conservación por parte de las entidades encargadas de salvaguardar los espacios protegidos en la región desde mediados del siglo XX.

TABLA 3 .

Porcentaje de especies arbóreas en el parque

\begin{tabular}{lrrr}
\hline $\begin{array}{c}\text { Procedencia } \\
\text { especies vegetales }\end{array}$ & Área protegida & Área arqueológica & Área recreativa \\
\hline Nativa & $27,63 \%$ & $32,89 \%$ & $32,73 \%$ \\
\hline Exótica & $72,37 \%$ & $67,11 \%$ & $67,27 \%$ \\
\hline
\end{tabular}

Fuente: elaboración propia

Por una parte, la dominancia de las especies exóticas en cada una de las categorías de uso conlleva a la determinación que especies como acacias (Acacia decurrens, A. melanoxylon), eucalipto (Eucalyptus globulus) y jazmín (Pittosporum undulatum) homogenizan el paisaje, aunque en algunas áreas permiten la representatividad de otras especies como el ciprés (Cupressus lusitanica) y el urapán (Fraxinus chinensis). Por otra, las especies nativas (presentes en menor número y porcentaje de dominancia) están representadas, principalmente, por especies como chicalá (Tecoma stans), sauce (Salix humboldtiana), sauco (Sambucus peruviana), alcaparro (Senna viarum), tibar (Escallonia paniculata), corono (Xylosma spiculifera), chilco (Baccharis latifolia) y drago (Cordia). 


\section{Distribución espacial}

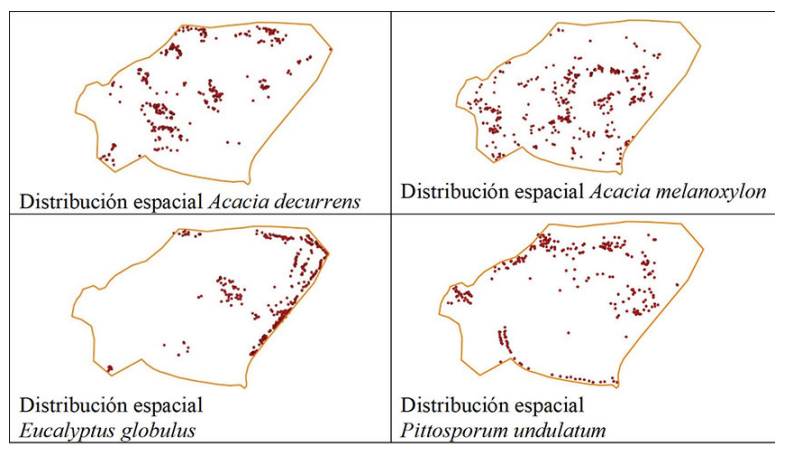

FIGURA 2 .

Distribución espacial especies exóticas.

Fuente: elaboración propia

Teniendo presente que se ha georreferenciado la totalidad de individuos vegetales arbóreos presentes en el parque arqueológico mediante el método gráfico (figuras 2 y 3 ), se procedió a determinar la distribución espacial de las principales especies vegetales (nativas e introducidas) presentes en el parque arqueológico, con el propósito de evaluar su grado de agregación o dispersión. Este mecanismo posibilita la identificación de mecanismos y factores que promueven la coexistencia y la diversidad vegetal en los ecosistemas.

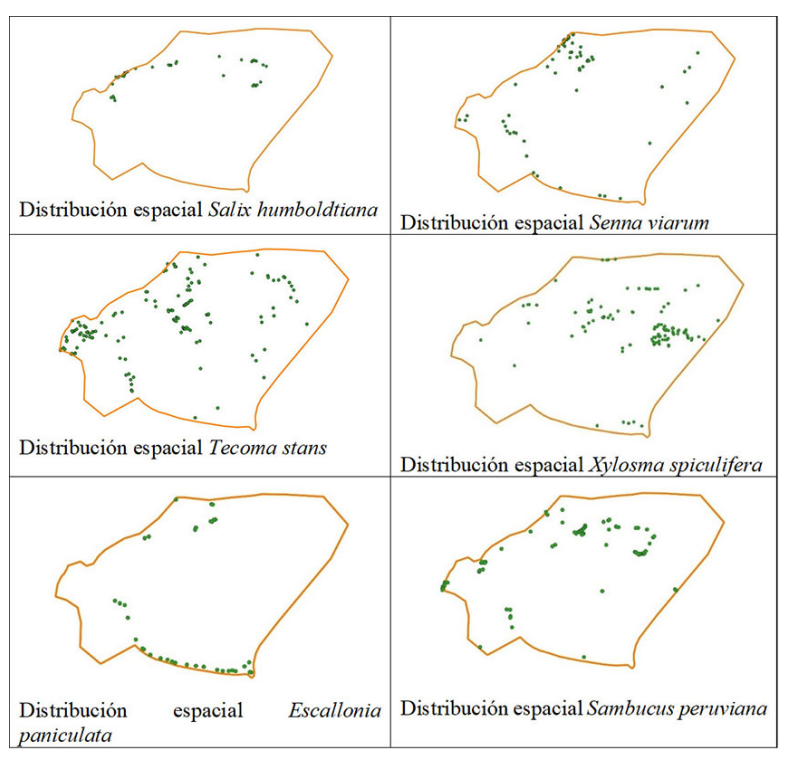

FIGURA 3 .

Distribución espacial especies nativas.

Fuente: elaboración propia

Las especies exóticas con mayor número de individuos presentan un comportamiento en el cual la población tiende a la agregación. Esto aplica para las especies Eucalipto (Eucalyptus globulus), Acacia (Acacia decurrens) y Jazmín (Pittosporum undulatum).

En adición, las especies nativas Chicalá (Tecoma stans), Alcaparro (Senna viarum), Corono (Xylosma spiculifera) y Sauce (Salix humboldtiana) presentan un patrón aleatorio que hace que sus poblaciones se noten dispersas frente a la vegetación total del parque, aunque en las poblaciones de Sauco (Sambucus peruviana) y Tibar (Escallonia paniculata) se evidencia su distribución agrupada, debido a que se han empleado en linderos (cercas vivas).

Estas diferencias significativas entre el comportamiento de distribución espacial de las especies introducidas frente a las nativas, hace que se presente cierta "territorialidad" de las especies exóticas, posiblemente 
provocada por sus condiciones alelopáticas, pero también por su fuerte influencia en el paisaje, en razón a que por formar fuertes conglomerados no permite la visibilidad de las especies nativas.

\section{Comportamiento de la vegetación en los últimos doce años}

El análisis de imágenes satelitales realizado para el 2004 y el 2015 permite evidenciar el incremento de la cobertura vegetal del área del parque arqueológico. Aunque no existe un inventario forestal para la época, que permita comparar los datos con los obtenidos en el presente estudio, las imágenes conllevan a deducir que la cobertura vegetal (proyección de las copas sobre el suelo) ha aumentado cerca de un 63\%. En la figura 4 se evidencia cómo para el 2004 la cobertura vegetal tenía un área de 88\$674 metros cuadrados y, para el 2015, dicha cobertura aumentó a 145聿02,42 metros cuadrados.

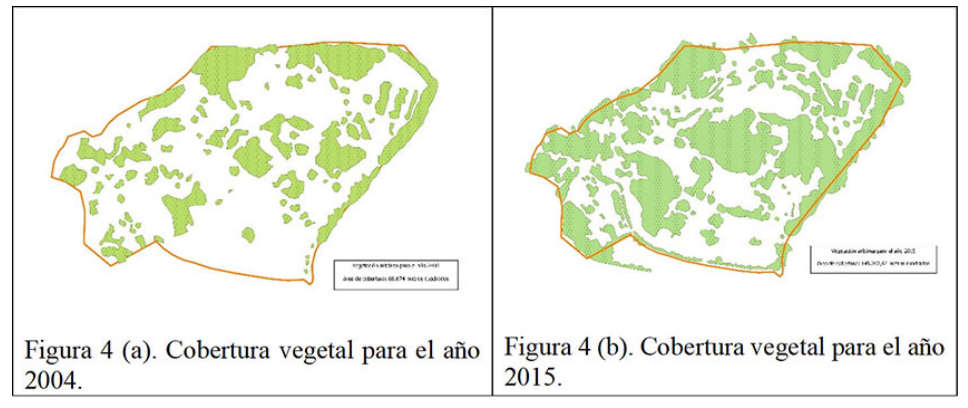

FIGURA 4 .

Cambios de vegetación para el periodo 2004 - 2015.

Fuente: elaboración propia basado en imágenes satelitales de Google Earth

Las áreas donde se localizan las especies exóticas han tenido un aumento en la cobertura superior a aquellas zonas donde se presentan las especies nativas. Las ventajas fisiológicas de la acacia (Acacia melanoxylon, A. decurrens), el eucalipto (Eucalyptus globulus) y el jazmín (Pittosporum undulatum), que permiten una tasa de crecimiento mayor; su condición alelopática y las escasas acciones silvícolas y de manejo de la regeneración natural, ha conllevado al incremento en el número de individuos de estas especies.

\section{Conclusiones}

El Parque Arqueológico “Piedras del Tunjo”, localizado en el municipio de Facatativá, constituido como un área de interacción y recreación para la comunidad, como un territorio de importancia y relevancia ecológica, al pertenecer a la estructura ecológica principal del municipio y el departamento, y cuyo eje funcional lo configuran sus relictos ancestrales (manifestaciones rupestres), que le otorgan un gran valor arqueológico para la Nación, ha sido objeto de esfuerzos institucionales que han buscado salvaguardar la riqueza histórica de gran relevancia y significancia para el territorio. Sin embargo, el desconocimiento de su esencia ha ocasionado que la intervención antrópica haya alterado (y en algunos casos, borrado), las huellas (pictogramas) de los primeros habitantes de la región.

El estudio del paisaje del parque se configura en un instrumento de relevancia para orientar su funcionamiento hacia un futuro, preservar su identidad patrimonial y su funcionalidad ecológica y de escenario recreativo. El paisaje refleja los procesos culturales y transformadores de la sociedad, y se configura como un factor que conlleva a la identidad de la comunidad frente a un escenario determinado. La vegetación, como elemento constituyente del paisaje, responde a las actuaciones de índole natural y gestiones antrópicas del territorio, lo que permite la evaluación de los procesos y cambios en el área. Su estudio a profundidad posibilita la realización de acciones de gestión para potencializar su multifuncionalidad y resaltar los diferentes valores (ecosistémicos, sociales y culturales) que están inmersos y hacen parte sustancial de su constitución, tanto en el parque arqueológico como en otras áreas similares en el territorio nacional. 
La conformación de este escenario trasciende las connotaciones ancestrales que permitieron su creación como área patrimonial, y es evidente su utilización como espacio de recreación y de importancia ecosistémica para la región. Ahora bien, la caracterización del paisaje del parque arqueológico a partir de la vegetación arbórea permite establecer la desarticulación entre la funcionalidad del área en los ámbitos cultural, recreativo y ecológico, frente a la descripción del entorno en cada una las categorías de uso establecidas en el lugar. Cerca del 70\% de los individuos arbóreos del parque corresponden a especies exóticas, cuyas características naturales, si bien han dado inicio a un aumento de la cobertura vegetal en el ltimo decenio, han provocado la disminución de la diversidad, ocasionada posiblemente por factores alelopáticos, al tiempo que han aumentado el riesgo y vulnerabilidad de la comunidad por ser propicias a la caída de ramas y al volcamiento.

La preponderancia de las especies exóticas surge como un eje distractor que no permite visualizar la potencialidad de este escenario y su gran valor en los ámbitos histórico y ecosistémico, aunado a la minimización del verdadero aporte cultural y recreativo de las especies nativas, ocasionado por el bajo nmero de individuos vegetales. De esta manera, el entorno, al menos desde un análisis de la vegetación, se desliga del propósito de conservación de este espacio.

Las "Piedras del Tunjo", como unidad de análisis, debe correlacionar los bienes arqueológicos, el espacio natural en que se circunscriben y el área recreativa empleada por la comunidad. El paisaje debe responder y actuar como eje articulador de la multifuncionalidad de este escenario para posibilitar su conservación y preservación. El uso, conservación y manejo racional parten del conocimiento del entorno en sus mltiples dimensiones, y favorecen los procesos sociales que arraiguen la comunidad a su identidad. De lo contrario, el acelerado crecimiento y el ritmo desarrollista provocará el detrimento y la pérdida de los valores culturales y ambientales de la región.

\section{Notas}

Este artículo es una toma los resultados de la tesis de maestría "Parque Arqueológico las Piedras de Tunjo. Escenario de cultura, recreación y valores ecosistémicos”, realizada en la Universidad Nacional de Colombia.

\section{Referencias}

lvarez-Ayuso, E., Otones, V., Murciego, A., García-Sánchez, A., \& Regina, I.S. (2013). Mobility and phytoavailability of antimony in an area impacted by a former stibnite mine exploitation. Science of The Total Environment, 449, 260-268. https://doi.org/10.1016/j.scitotenv.2013.01.071

Aponte-García, G. (2003). Paisaje e identidad cultural. Tabula Rasa, (1), 153-164.

Botiva-Contreras,. (2011). El origen de las piedras y su entorno. Facatativá "Al final de la llanura". En D. MartínezCelis, y C. Botiva-Contreras (Coords.), Compendio documental del Parque Arqueológico de Facatativá (pp. 1-59). Facatativá, Colombia: Alcaldía Municipal de Facatativá.

Cobo-Borda, J. G. (2010). Recuerdo de un novelista sudamericano: Eduardo Caballero Calderón. Recuperado de http ://www.mcarts.com/cobo/ensayos/caballero-calderon5.html

Consejo de Europa. (2000). Convenio Europeo del Paisaje. Recuperado de http://www.upv.es/contenidos/CAMUN ISO/info/U0670786.pdf.

Organización de las Naciones Unidas para la Agricultura y la Alimentación (FAO). (2003). Tesauro plurilingüe de tierras. Recuperado de http://www.fao.org/docrep/005/X2038S/X2038S00.HTM

Gómez-Alzate, A. (2012, noviembre). Criterios metodológicos para el análisis de la calidad visual del paisaje urbano y su sostenibilidad. Ponencia presentada en $1^{\circ}$ Congreso internacional en gestión y control de la calidad del aire, auditiva y visual, Bogotá.

Gómez-Zotano, J., y Riesco-Chueca, P. (2010). Marco conceptual y metodológico para los paisajes españoles. Aplicación a tres escalas espaciales. Sevilla: Consejería de Obras Públicas y Vivienda, Centro de Estudios Paisaje y Territorio. 
Instituto Colombiano de Antropología e Historia (Icanh). (2005). Plan de Manejo Parque Arqueológico de Facatativá "Las Piedras de Tunja". Bogotá: Icanh.

Martínez, D. (2011). El lugar de las piedras. El contexto regional. En D. Martínez-Celis y Á. Botiva-Contreras (Coords.), Compendio documental del Parque Arqueológico de Facatativá (pp. 13 - 14). Facatativá, Colombia: Alcaldía Municipal de Facatativá.

Másmela-Díaz, P. (2010). El paisaje como elemento de la ordenación territorial. Un análisis de paisaje desde su enfoque visual en el borde centro oriental de Medellín, Colombia. Medellín: Universidad Nacioal de Colombia.

Montoya-Ayala, R., Padilla-Ramírez, J., y Stanford-Camargo, S. (2003). Valoración de la calidad y fragilidad visual del paisaje en el Valle de Zapotitlán de las Salinas, Puebla (México). Boletín de Asociación de Geógrafos Españoles, 35, 123-136.

Muñoz-Camacho, L. (2015). Paisaje Funcional. Disfunción de límites sociales. Bogotá: Universidad Católica de Colombia.

Muñoz-Criado, A. (2012). Guía metodológica. Estudios del paisaje. Lugar de edición: Conselleria de Infraestructuras, Territorio y Medio Ambiente.

Olivos-Lombana, A. (2011). Las piedras como memoria. Historia del Parque Arqueológico de Facatativá. En D. Martínez-Celis y Á. Botiva-Contreras (Coords.), Compendio documental del Parque Arqueológico de Facatativá (pp. 191 - 202). Facatativá, Colombia: Alcaldía Municipal de Facatativá.

Orejas-Saco-del-Valle, A. (2001). Los Parques Arqueológicos y el Paisaje como Patrimonio. Revista sobre Arqueología en internet, (3)1, agregar páginas del artículo.

Pérez-Bustamante, L. y Parra-Ponce, C. (2004). Paisajes culturales: el parque patrimonial como instrumento de revalorización y revitalización del territorio. Theoria, 13, 9-24

Sánchez-Palencia, J., Fernández-Posse, M., Fernández-Manzano, J., Orejas-Saco-del-Valle, A., Álvarez-González, Y., López González, L., y Pérez-García, L. (1996). Las zonas arqueológicas como paisajes culturales: El Parque Arqueológico de las Médulas (León). Complutum Extra, 6(2), 383-403.

\section{Licencia Creative Commons CC BY 4.0}

Cómo citar este artículo: Díaz, W. R. (2018). Análisis del paisaje en el Parque Arqueológico "Las Piedras del Tunjo", mediante la caracterización vegetal arbórea". Ambiente Y Desarrollo, 22(42), 1-12. https:// doi.org/10.11144/Javeriana.ayd22-42.appa 